\title{
Photoprotection by carotenoids of Plantago media photosynthetic apparatus in natural conditions*
}

\author{
Tamara Golovko $\bowtie$, Olga Dymova, Ilya Zakhozhiy, Igor Dalke and Galina Tabalenkova \\ Institute of Biology, Komi Science Centre, Ural Branch of Russian Academy of Sciences, Syktyvkar, Russia
}

The study of daily changes in photosynthetic rate, of energy used in photochemical and non-photochemical processes, and of carotenoid composition aimed at evaluating the role of xanthophyll cycle (XC) in protection of hoary plantain plants (Plantago media) in nature. The leaves of sun plants differed from shade plants in terms of $\mathrm{CO}_{2}$ exchange rate and photosynthetic pigments content. The total pool XC pigments and the conversion state increased from morning to midday in sun plants. An increase in zeaxanthin content occurred concomitantly with the violaxanthin decrease. About $80 \%$ violaxanthin was involved in conversion. The maximum of zeaxanthin in XC pigments pool was $60 \%$. The conversion state of XC was twice as lower in shade plants than that in sun plants. The photosynthesis of sun leaves was depressed strongly at midday, but changes of maximum quantum yield of PS2 $\left(F_{v} / F_{m}\right)$ were not apparent at that time. The coefficient qN (non-photochemical quenching) in the sun leaves changed strongly, from 0.3 to 0.9 as irradiance increased. The direct relation between heat dissipation and the conversion state of XC in plantain leaves was revealed. Thus, plantain leaves were found to be resistant to excess solar radiation due to activation of qN mechanisms associated with the XC de-epoxidation.

Key words: carotenoids, xanthophylls cycle, photoinhibition, photoprotection, Plantago media

Received: 17 October, 2011; accepted: 01 March, 2012; available on-line: 17 March, 2012

\section{INTRODUCTION}

Light is the most important environmental factor for plants. As energy source, light is converted to chemical energy through photosynthesis by which nearly all energy enters our biosphere. Photosynthetic rate depends on photo flux density (PFD). But not all light energy absorbed by pigments is used for photosynthetic carbon dioxide fixation. Light stress is the normal situation for the photosynthesis in plants even in the temperate region. Various factors (temperature, drought, nutrient deficiency, etc.) are known to have consequences on the photosynthetic apparatus, and photoinhibition may be often observed under these environmental conditions. To cope with absorption of excessive light and its consequences, the photosynthesizing organisms have evolved a series of photoprotective mechanisms. Light absorption reduction and excess light energy dissipation by photosystems are the major aspects of plant photoprotective mechanisms. This energy dissipation becomes obvious by the non-photochemical quenching, which is a mixture of different underlying processes. In many cases the degree of non-photochemical energy dissipation is closely correlated with the activity of xanthophyll cycle (XC) (Demmig-Adams, 2003). The purpose of this study is to examine simultaneous changes in photosynthesis, energy used in photochemical and non-photochemical processes and photoprotection through the regulation of $\mathrm{XC}$ in hoary plantain plants (Plantago media) in nature.

\section{MATERIAL AND METHODS}

Plantago media is a perennial, short-rhizome taprooted herb. Plantain is common in floodplain meadows and sparse forests. The study site $\left(62^{\circ} 45^{\prime} \mathrm{N}, 55^{\circ} 49^{\prime} \mathrm{E}\right)$ was located in the South Timan on the left bank of the river Soiva. Experiments were performed in the first half of July in 2007 and 2010. Two groups of plants selected for experiments. The first group grew on the southeast-facing scree slope with sparse vegetation (sun plants). The second group grew on the narrow terrace at the foot of a slope in the dense herbage (shade plants). Measurements of microclimate parameters were performed with portable station (Data Logger LI-1400, USA). Leaf $\mathrm{CO}_{2}$-exchange rate were measured with an infrared gas analyzers (LCPro+ (ADC, UK). Chlorophyll a (Chl a) fluorescence was measured with a portable fluorometer (PAM-2100, Walz, Germany). Leaf samples were frozen in liquid nitrogen and stored at $-76^{\circ} \mathrm{C}$. Photosynthetic pigments were extracted with acetone. The pigment content was determined spectrophotometrically (UV-1700, Shimadsu, Japan). Individual Car were separated using the reversed-phase high-performance liquid chromatography (HPLC) system (Knauer, Germany) equipped with a column $4.0 \times 250 \mathrm{~mm}$ Diasphere-110-C18NT. The pigments were eluted for $34 \mathrm{~min}$ with gradient solvent systems A (acetonitrile:methanol:water, 75:12:4, v/v) and B (methanol:ethyl acetate, 68:32, v/v) at a flow rate of 2 $\mathrm{ml} / \mathrm{min}$. Identification of Car was carried out by comparing of HPLC retention times with corresponding standarts. The de-epoxidation level of XC pigments was calculated according to equation: DEPS $=(\mathrm{Z}+0.5 \mathrm{~A}) /$ $(\mathrm{V}+\mathrm{A}+\mathrm{Z})$, where $\mathrm{Z}, \mathrm{A}$, and $\mathrm{V}$ designate zeaxanthin, antheraxanthin, violaxanthin, respectively.

\section{RESULTS AND DISCUSSION}

Plants growing on the open slope in full sun site, received substantially more light and heat, than plants

e-mail: golovko@ib.komisc.ru

*Presented at the 16th International Symposium on Carotenoids, 17-22 July, 2011, Kraków, Poland

Abbreviations: Car, carotenoids; DEPS, de-epoxidation level of XC pigments; XC, xanthophyll. 
Table 1. Area (S), leaf mass per area (LMA) and content of pigments in Plantago plants

Data are mean \pm SE of 15-20 leaves for $S$ and LMA, and of 5 samples for pigments

\begin{tabular}{lcccccccc}
\hline \multirow{2}{*}{ Plants } & \multicolumn{3}{c}{$\mathrm{S}, \mathrm{sm}^{2}$} & \multicolumn{2}{c}{ LMA, $\mathrm{g} \mathrm{dw} / \mathrm{dm}^{2}$} & \multicolumn{2}{c}{ Chlorophylls, $\mathrm{mg} / \mathrm{g} \mathrm{dw}$} & \multicolumn{3}{c}{ Carotenoids, mg/g dw } \\
\cline { 2 - 9 } & 2007 & 2010 & 2007 & 2010 & 2007 & 2010 & 2007 & 2010 \\
\hline Sun & $8.3 \pm 0.8$ & $6.5 \pm 0.4$ & $0.9 \pm 0.1$ & $0.9 \pm 0.2$ & $3.1 \pm 0.4$ & $2.8 \pm 0.3$ & $0.79 \pm 0.08$ & $0.75 \pm 0.02$ \\
Shade & $18.1 \pm 1.4$ & $25.1 \pm 1.5$ & $0.4 \pm 0.1$ & $0.5 \pm 0.1$ & $5.4 \pm 0.3$ & $4.5 \pm 0.2$ & $1.16 \pm 0.03$ & $0.97 \pm 0.04$ \\
\hline
\end{tabular}

Table 2. Daily changes of xanthophyll cycle pigments de-epoxidation (DEPS) in Plantago media leaves (\%) July 2010 Data are mean of 6 measurements for each point

\begin{tabular}{llllll}
\hline \multirow{2}{*}{ Plants } & \multicolumn{4}{l}{ Time, hours } \\
\cline { 2 - 6 } & $06: 00$ & $10: 00$ & $15: 00$ & $19: 00$ & $23: 00$ \\
\hline Sun & 22 & 77 & 54 & 15 & 12 \\
Shade & 20 & 56 & 40 & 17 & 9 \\
\hline
\end{tabular}

inhabiting in the dense herbage. The highest irradiance was 200-300 and 1300-1600 $\mu \mathrm{mol} /\left(\mathrm{m}^{2} \mathrm{~s}\right)$ in shade and sun sites, respectively. Table 1 summarizes the results of morphological and physiological acclimation of plantain to irradiance. Sun-adapted plants (S-plant) formed leaves with lower area and higher dry mass per area as compared to shade-adapted plants (SH-plant). The content of the photosynthetic pigments strongly depends on growth conditions. Although leaves that were developed on full sunlight had reduced pigment concentration, the ratio Car/Chl was greater than in SH-plants.

The maximal photosynthesis rate in S-plant leaves was 10-12 $\mu \mathrm{mol} \mathrm{CO} /\left(\mathrm{m}^{2} \mathrm{~s}\right)$; while in SH-plants value of this index did not exceed $4 \mu \mathrm{mol} /\left(\mathrm{m}^{2} \mathrm{~s}\right)$. The photosynthetic rate $(\mathrm{Pn})$ in the $\mathrm{S}$-plant leaves was highest in the morning and the nearly full depression of Pn was observed at noon hours. The decreasing of Pn was not so significant in SH-plant leaves. HPLC-analysis revealed the presence of $\beta$-carotene and xanthophylls in Car pool. Lutein was predominated among xanthophylls and took $70 \%$ of total Car. The content and the conversion state of XC pigments increased significantly from morning to midday in S-plants (Table 2). The percentage of $\mathrm{V}$ in VAZ pool was the greatest, 85-90\%, at midnight and decreased by 4 and 2 times in S- and SH-plant leaves at noon hours, respectively. An increase in $Z$ content occurred concomitantly with the $\mathrm{V}$ decrease. Maximum part of $\mathrm{Z}$ in $\mathrm{VAZ}$ pool was $60 \%$ in the S-plant leaves. DEPS was signifi- cantly lower in SH-plants than that in S-plants, especially in the midday hours. We used epoxidase inhibitor salicylaldoxime to evaluate the part of $\mathrm{V}$, which was not involved in conversion. It was about $25 \%$ and $15 \%$ of total $\mathrm{V}$ pool in $\mathrm{SH}$ - and S-plant leaves respectively.

The ratio $\mathrm{F}_{\mathrm{v}} / \mathrm{F}_{\mathrm{m}}$, which represents the PSII maximum photochemical activity, remained relatively high (approx. 0.8) through the day in July 2007. A moderate decrease of $\mathrm{F}_{\mathrm{v}} / \mathrm{F}_{\mathrm{m}}$ at midday for S-plant leaves and in the afternoon for SH-plant leaves was noted in warmer July 2010 (Table 3). The coefficient of photochemical (qP) and non-photochemical (qN) quenching of $\mathrm{Chl} \mathrm{a}$ fluorescence in S-plant leaves changed strongly as irradiance increased. The value of qN was smaller and changed less drastically in SH-plant leaves. The qP coefficient in SH-plant leaves was maintained on the high level during the whole day.

These results, together with earlier reported data (Golovko et al, 2011), showed that under excessive light, up to $90 \%$ of the absorbed energy may be dissipated via the qN pathway in hoary plantain plants, which were grown on the open slope and were adapted to high light conditions for long-time. The exact role of zeaxanthin in the qN-mechanisms is still under debate Janhs et al, 2009). The close relation between heat dissipation and the conversion state of XC pigments in plantain leaves was revealed. The part of light energy dissipated as heat in LHC PSII of plantain hoary S- and SH-plant leaves in midday hours amounted to $75 \%$ and $30 \%$, respectively. In conclusion, our data support the idea, that carotenoids play an important role in protection of photosynthetic apparatus and adaptation of Plantago media plants under natural conditions.

\section{Acknowledgements}

This work was supported by the grant from the Ural Branch of the Russian Academy of Sciences (12-Y-41008).

Table 3. The leaf chlorophyll fluorescence parameters and heat dissipation (D) (July, 2010) Data are mean \pm S.E. of 25 -30 measurements for each point

\begin{tabular}{llllll}
\hline Time, $\mathrm{h}$ & $\mathrm{PAR}, \mu \mathrm{mol} / \mathrm{m}^{2} \mathrm{~s}$ & $\mathrm{~F}_{\mathrm{v}} / \mathrm{F}_{\mathrm{m}}$ & $\mathrm{qP}$ & $\mathrm{qN}$ & $\mathrm{D}$ \\
\hline Sun plants & & & & & $0.26 \pm 0.01$ \\
\hline 4.00 & $126 \pm 6$ & $0.80 \pm 0.01$ & $0.90 \pm 0.01$ & $0.30 \pm 0.02$ & $0.58 \pm 0.02$ \\
6.00 & $1201 \pm 35$ & $0.70 \pm 0.02$ & $0.44 \pm 0.04$ & $0.80 \pm 0.02$ & $0.75 \pm 0.01$ \\
11.00 & $1631 \pm 36$ & $0.71 \pm 0.01$ & $0.49 \pm 0.05$ & $0.91 \pm 0.01$ & $0.63 \pm 0.03$ \\
14.00 & $1228 \pm 48$ & $0.74 \pm 0.01$ & $0.54 \pm 0.06$ & $0.83 \pm 0.03$ & $0.26 \pm 0.01$ \\
17.00 & $84 \pm 2$ & $0.73 \pm 0.01$ & $0.96 \pm 0.01$ & $0.26 \pm 0.02$ & \\
\hline Shade plants & & & & $0.366 \pm 0.035$ & $0.24 \pm 0.01$ \\
\hline 6.00 & $63 \pm 17$ & $0.80 \pm 0.01$ & $0.862 \pm 0.045$ & $0.354 \pm 0.035$ & $0.29 \pm 0.02$ \\
11.00 & $167 \pm 30$ & $0.77 \pm 0.01$ & $0.845 \pm 0.019$ & $0.232 \pm 0.026$ & $0.25 \pm 0.01$ \\
16.00 & $104 \pm 24$ & $0.73 \pm 0.01$ & $0.901 \pm 0.019$ & & \\
\hline
\end{tabular}




\section{REFERENCES}

Demmig-Adams B (2003) Linking the xanthophylls cycle with thermal energy dissipation. Photosynth. Res 76: 73-80.

Golovko TK, Dalke IV, Zakhozhiy IG, Dymova OV, Tabalenkova GN (2011) Functional plasticity of photosynthetic apparatus and its resistance to photoinhibition in Plantago media. Russ J Plant Physiol 58: 549-559.
Jahns P, Latowski D, Strzalka K (2009) Mechanism and regulation of the violaxanthin cycle: The role of antenna proteins and membrane lipids. Biochim Biophys Acta 1787: 3-14. 